\title{
Increased usage of Smartphones in Medicine, an opportunity for Medical Cytogenetics
}

\author{
Arlay C. López $\mathbb{D}^{\circ}$, Michel S. Torres $\mathbb{D}^{+}$, Nereida G. García $\mathbb{D}^{-}$, \\ Ursulina S. Mayedo ${ }^{\circ}$, Luis A. Méndez-Rosado \\ National Center of Medical Genetics, \\ 146 St., Havana, 10300, Cuba \\ Corresponding author: Arlay C. López (arlay@cngen.sld.cu)
}

\begin{abstract}
Background: The progressive availability at a worldwide scale of smartphones with bigger computing power and equipped with high quality cameras advertise a better usage for this equipment by health care professionals. In addition, the possibility of acquiring very fast images and sharing them on the Internet by developing different applications increases the range of opportunities to diagnose diverse pathologies. The aim of the study: To carry out a bibliographic review on previously exposed topic and share the experience of the cytogenetics laboratory of the National Center of Medical Genetics in the introduction of smartphones and their use in cytogenetics. Materials and methods: The web search engine Google Scholar was consulted for the terms "smartphone", "medicine", "diagnosis" and "clinical images". Pubmed database was also consulted for the same terms. Results: Several articles were retrieved from first world countries and also from developing countries. The authors proposed to apply smartphones technologies to make cheaper the dissemination of information for longdistance consultations. Conclusion: The use of "smartphones" makes it easier to perform tasks at a lower cost than those involving the use of professional equipment that has been the only option available to researchers within the health sciences until now.
\end{abstract}

Keywords: smartphone; diagnosis; distance counseling; health services; developing countries

For citation: López AC, Torres MS, García NG, et al. Increased usage of Smartphones in Medicine, an opportunity for Medical Cytogenetics. Research Results in Biomedicine. 2020;6(4):457-465. DOI: 10.18413/2658-6533-2020-6-4-0-2

Introduction. Modern times have brought about a gigantic advance in the media, especially advances in mobile telephony and the Internet, which can be used to improve communication between specialists in the health system. Smartphones offer an attractive possibility to solve problems of accessibility, quality, effectiveness, efficiency and costs of health care [1].

A growing percentage of citizens in developing countries have greater purchasing power for smartphones, which supports the development of applications for telemedicine. The use of hardware and software architecture in smartphones to improve health care is an emerging issue that allows the implementation of various technologies associated with telemedicine on a phone including electrical impedance tomography, electrocardiography, fluorescence microscopy and lens-less microscopy on a chip [2]. 
In the latest generation, in addition to high-resolution cameras, they have advanced multi-core processors, microchips designed to handle graphics and innovative operating systems that provide a portable platform to run sophisticated medical screening applications and provide diagnostic services to patients in their care facilities at a very affordable price [3]. In dermatology, telephones are currently used to carry out tele-dermoscopy $[4,5]$.

Increasingly in the field of cytopathology digital images are being used for teletechnology, online education, clinical consultation, web-based learning, quality assurance and secondary applications such as image analysis [6]. The emerging use of mobile communications and network technology applications for use by healthcare personnel has been referred to as mHealth. Its successful implementation ensures that the right information is available in the right place, in the right way and at the right time. These technologies are gaining space and could one day become global [7].

In our country, this branch of technology has been developing with more than 5 million telephone lines sold and the establishment of a data exchange service through cellular technology with $4 \mathrm{G}$ generation. In addition to the large number of smartphones purchased by medical professionals, either at home or abroad, which allow them to perform tasks beyond those expected from a communication device.

On the other hand, the difficulties for the purchase and renewal of advanced technological equipment, designed specifically for use in assistance/research that allows the capture and processing of images, makes it very important to be able to capture images even when they have a lower quality but with the possibility of capturing what we want to record as a record that can be valued among specialists and also used in teaching for the preparation of professionals. The objective is to carry out a bibliographic review on this previously exposed topic and the experience of the cytogenetics laboratory of the National Center of Medical Genetics in the introduction of smartphones for its use in cytogenetics.
Methods. For the search of bibliographic materials, the Internet academic Google search site was consulted with the following terms: "smartphone", "medicine", "diagnosis" and "clinical images", as well as the Pubmed database. Thirty-six scientific articles were retrieved and those reporting the use of smartphones were selected to facilitate the acquisition of images of diagnostic or educational value, with or without a coupled microscope, and the assessment of this use in clinical practice. Most of the articles retrieved are less than a decade old, but some articles just over a decade old were included because they show the firsts steps in using smartphones to record and send various types of data with diagnostic value for consultation.

Development. The increasing possibility of remote exchange of massive amounts of data is changing the way scientists perceive, study and analyze the world and this is likely to change the nature of the biological record in terms of techniques, practices and the relationships between experts and non-experts [8].

Rapid improvements in the technical specifications and cost efficiency of electronic products have propitiated the emergence of devices that can be used for high performance imaging. There are low-cost, high-quality digital cameras on the market with image sensors of more than $20 \mathrm{MP}$ [9]. Smartphones also have sensors of lower quality than the scientific-grade CCDs used in scientific image capture, but the gap between them has been shortening with the advance of technology. With each generation there has been a significant improvement in hardware and software specifications. Cellular integrated cameras, in particular, have been improved with each new model. They are potentially capable of taking high quality photomicrographs from slides through a microscope [10].

Several studies have addressed the use of compact digital cameras or cell phone cameras for biomedical imaging applications. Common cameras have even been used in imaging techniques for fluorescence in a wide variety of locations, pathological analysis, and the integrated camera of cell phones has been 
applied with utility in the clinic [9]. Other authors prefer to test the different options on the market and advise one option or another depending on several tested parameters directly related to the quality of the image to be stored [10].

Use of smartphones in studies that require microscopy. Microscopy is an essential basic technique used in both pathology and microbiology for diagnosis and research work. With the advent of digital imaging, the role of microscopy has been boosted in the academic and research fields, as well as in advising on digital and slide images. Among the possibilities offered by telemedicine, the one that arouses most interest is that associated with microscopy, since it would allow the diagnosis of very common infections in developing countries. An example is the identification of an infection with malaria in countries where this disease is endemic [1,2]. The need to diagnose diseases in resource-limited conditions is well known and has inspired many researchers to study the possibilities of implementing a simple, low-cost microscopy system based on cameras integrated into mobile phones. Such a system would have the advantage of being widely spread around the world through telephone networks and the possibility of the imaging power of telephones to create portable devices for disease screening and diagnosis [11]. Options have even been implemented for the early detection of cancerous lesions using a device that articulates with an ordinary digital camera [12].

Several initiatives have previously shown that smartphones can be used to photograph through a microscope or be modified to serve as a microscope [13-18]. Portable devices have even been developed to be able to take phase-contrast images by using LED lights that strike at different angles to create contrast detectable by the smartphone camera [5].

The technique used to capture images through a microscope is known as microphotography and is very useful for documenta- tion, consultation and teaching. The best images are obtained using specialized digital cameras that are mounted on microscopes where the images obtained are recovered and processed using a proprietary computer program. These systems are very expensive and are often not available for low resource countries. Smartphones, on the other hand, have image capture and processing capabilities and are widely distributed among clinic professionals, which considerably reduce initial costs. A small number of products in the latter category in both the research and commercial stages have been evaluated by clinicians, but all are made exclusively for phones known as IPhones, which are still very expensive [19].

While webcams produce poor images, DSLR camera adapters are difficult to use. However, phones with $8 \mathrm{mp}$ on the back camera or higher are capable of taking clear pictures, which can be stored in the phone itself, transferred to a computer or shared with contacts [20, 21]. Commercially available microscope adapters such as the Magnifi, Skylight, and Snapzoom adapters can also be used (Figure 1). Adapters stabilize the picture taking process through the microscope [10]. Among the options to replace the use of adapters on the market, which are prohibitively expensive, several variants have been introduced, including the use of an illuminoscope, which consists of a piece of some thick material that surrounds the eyepiece and allows easy adjustment of the distance for focusing the image, relative smartphone stabilization, and removal of ambient light [3].

On the other hand, taking photomicrographs using the camera of hand-held smartphones is becoming increasingly recognized as a valid technique for obtaining useful images. This requires a phone with a minimum of $8 \mathrm{MP}$ in its rear camera, an appropriate binocular microscope, good ambient lighting and steady hands [21]. The technique was described by Morrison in 2013 and several papers have been published on the subject $[22,23]$. 


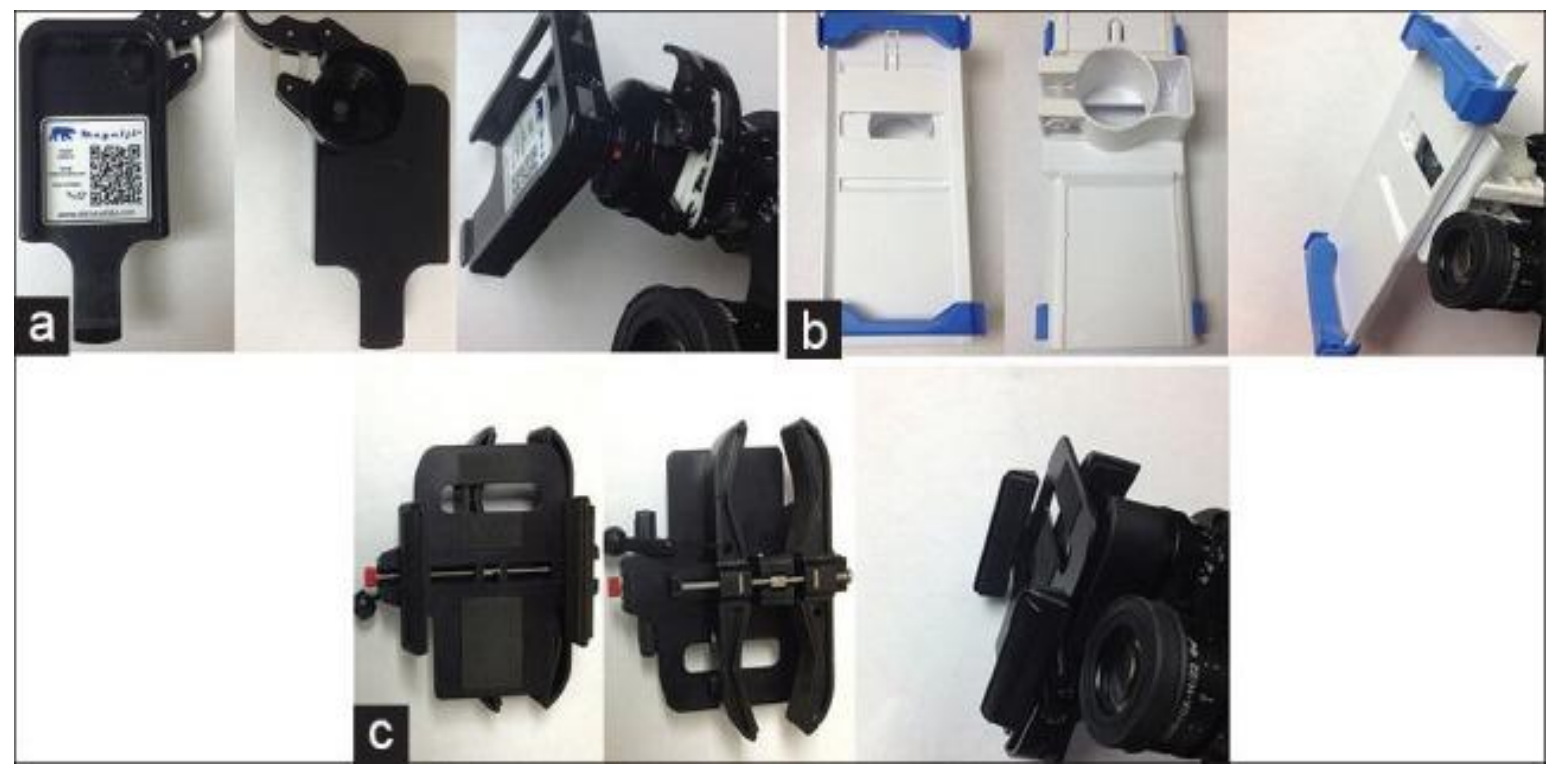

Fig. 1. Selected images of smartphone adapters that can be attached to a microscope.

(a) Magnifi adapter (b) Skylight adapter (c) Snapzoom adapter

Recently, several smartphone adapters have emerged to allow the user to fix the phone to the microscope [10]. Elements have even been introduced that allow the smartphone to be converted into a portable device for viewing in bright field, dark field and also in contrast to a multi-contrast platform that employs LED elements [24].

It has been a constant intention of several authors to achieve adapters to fix a smartphone to a microscope so that this adapter is cheap and functional from a technical point of view [25]. In their attempt to further lower the costs of imaging through mobile phones, suggestions have emerged for the handcrafted production of phone adapters that allow images to be taken without much manual skill on the part of the analyst [26]. It has even been suggested that they have been used for semen quality studies to diagnose male infertility at home, using a device with a microchip to which the sample is added and then connected to the telephone, which facilitates another type of study for which microscopy and other highly expensive resources are necessary [27].

The emerging market for technology associated with mobile telephony and its use in the health sector is expanding rapidly and is connecting even the most remote areas of the world. The distribution of diagnostic images on the telephone network for knowledge sharing, feedback and quality control is a logical innovation [1].

Application of mobile technology in the Clinical Cytogenetics Laboratory. In the Cytogenetics laboratory of the National Center of Medical Genetics in Havana, the smartphone has been used as a way to be able to quickly register an image of interest, as long as its purpose is not the publication of a case report and even this exception can be ignored if the image allows the identification beyond the doubt of the identified health problem. For this purpose, different models of telephone have been used, which, depending on their technical characteristics, allow a heterogeneous image quality (Figure 2).

Recently, in our lab, valuable images has been captured through the eyepiece with a mobile phone for educational purposes (Figure 3 and 4) resulting in a very reliable option when the specialist lacks of a camera attached to a microscope (Figure 5). 


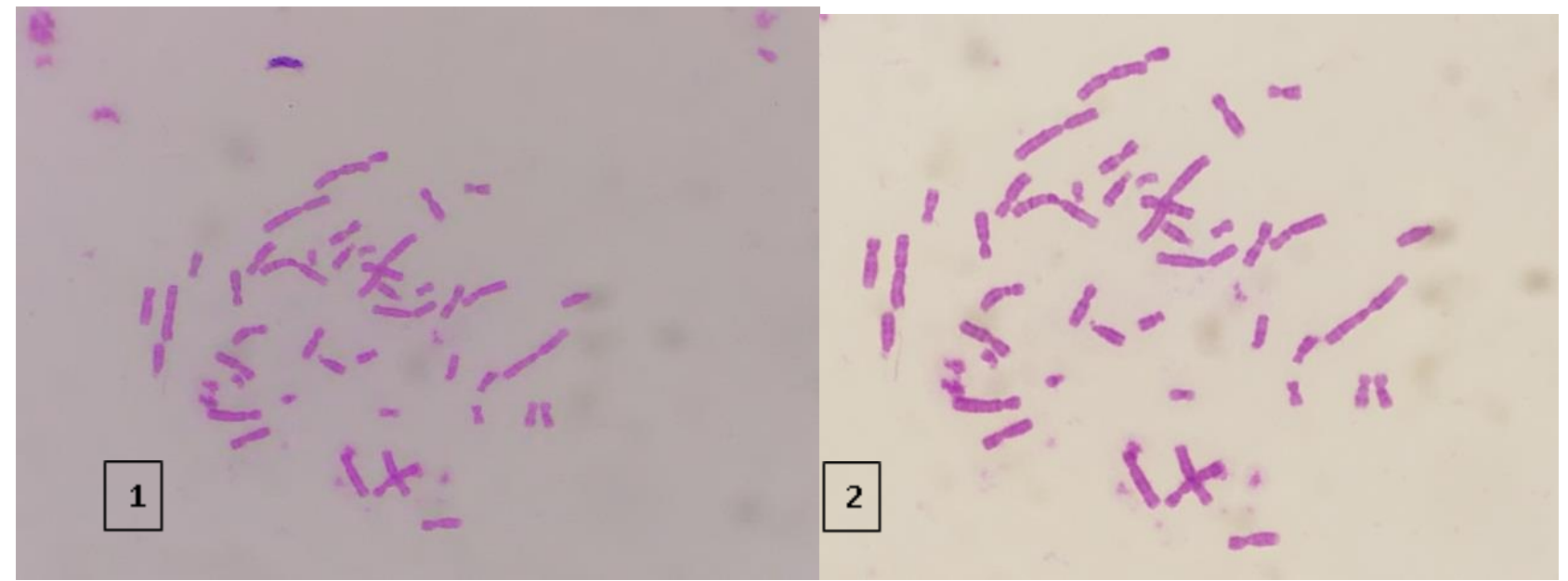

Fig. 2. Two microphotographs taken at the Cytogenetics Laboratory of the National Center of Medical Genetics of Cuba. On the left (1) a metaphase cell captured with an Alcatel Flint 5054 phone using the maximum zoom. On the right (2) another metaphase cell captured with a Samsung Galaxy Note 9 phone using 3.5x zoom

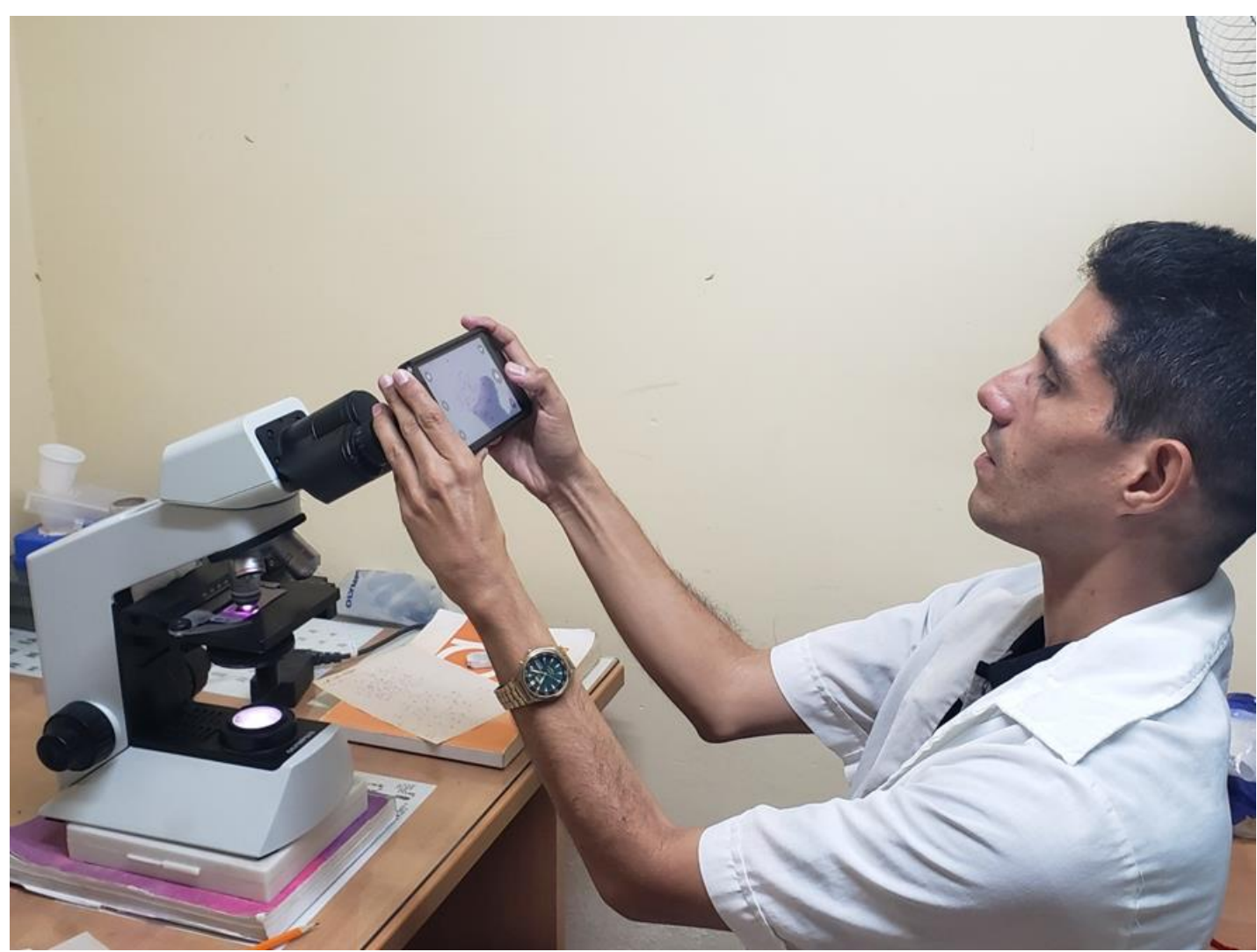

Fig. 3. Researcher capturing an image with a smartphone through the eyepiece of a microscope 


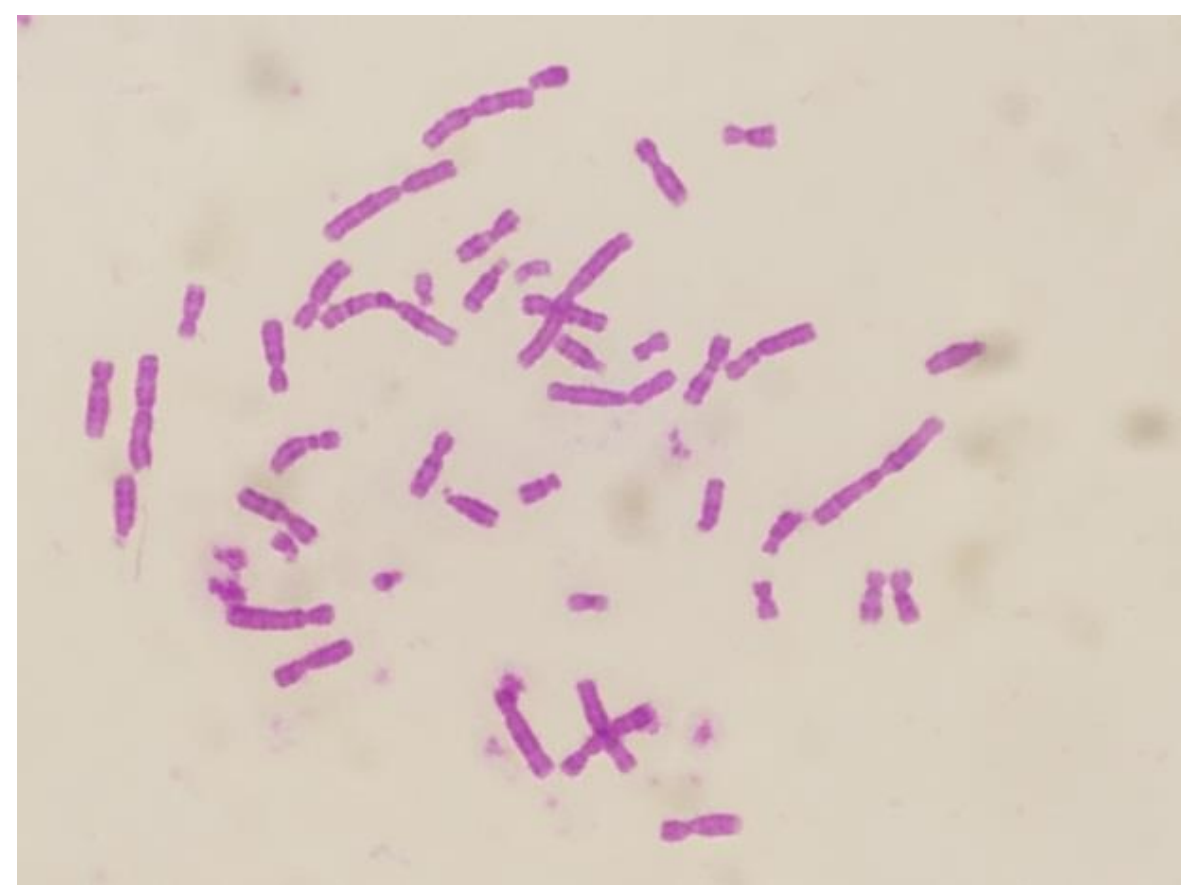

Fig. 4. Image captured with a smartphone through the eyepiece of a microscope

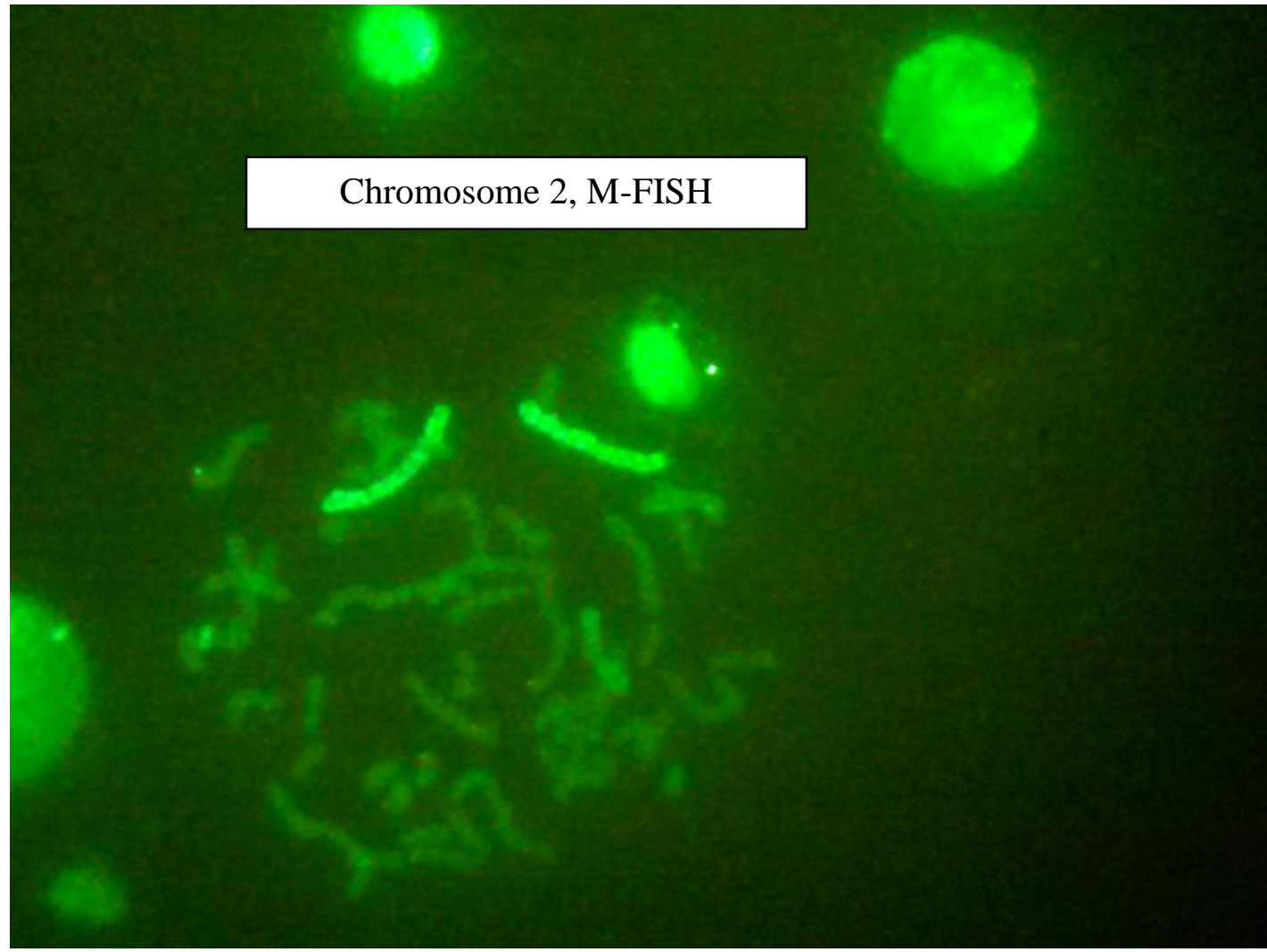

Fig. 5. Identification of chromosomes 2 in a preparation by the M-FISH method in the Cytogenetics Laboratory

Cuba has a national network dedicated to genetic medicine whose leading centre is the National Centre of Medical Genetics. The cytogenetics laboratory of this institution is a national reference laboratory [28], where sev- eral generations of cytogeneticists from Cuba and different Latin American countries have been trained. This circumstance has caused this laboratory and its specialists to be regularly consulted for the exchange of technical 
and diagnostic opinions. Mobile telephony has played a very efficient role in this process, mainly by sending images taken directly from the microscope with the phone camera.
Below we show the images taken in other laboratories and which have been sent for consultation with our cytogenetic specialists (Figure 6).

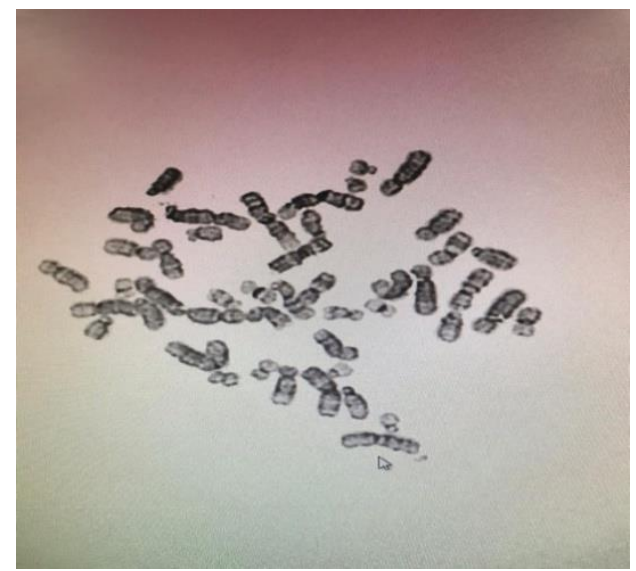

Fig. 6. Image received by our laboratory from a genetic specialist of another institution where an addition to the short arm of chromosome 10 is suspected. Marked by an arrow

Conclusions. The elements generally used to take images of scientific value are highly expensive, but other components can be obtained that allow photo and video to be taken in low-cost cameras within the reach of the public [29]. With the costs of medical services increasing throughout the world, there is a need to push for reducing the costs and complexity of medical devices. In addition, with a growing demand for high standards of care in regions where the medical infrastructure is below the level found in developed countries, the development of portable devices that can transmit relevant information to experts located over long distances is likely to have a quantitative and qualitative impact.

In cytogenetics, photomicrographs provide a mean of sharing information obtained from a slide for consultation, education, documentation and publication. Traditional image acquisition usually involves the use of units with a permanent camera integrated into a microscope, a computer and often a proprietary software for capturing and processing. Meanwhile, a novel approach to digital capture of microscopic images takes advantage of the development of smartphones placed over the eyepiece of microscopes.

\section{Financial support}

No financial support has been provided for this work.

\section{Conflict of interests}

The authors have no conflict of interest to declare.

\section{References}

1. Tuijn CJ, Hoefman BJ, Van Beijma H, et al. Data and image transfer using mobile phones to strengthen microscopy-based diagnostic services in low and middle income country laboratories. PLoS ONE. 2011;6(12):e28348. DOI: https://doi.org/10.1371/journal.pone.0028348

2. Zhu $\mathrm{H}$, Yaglidere $\mathrm{O}, \mathrm{Su} \mathrm{T}-\mathrm{W}$, et al. Cost-effective and compact wide-field fluorescent imaging on a cell-phone. Lab on a Chip. 2011;11(2):315-22. DOI: https://doi.org/10.1039/C0LC00358A

3. Nair N, Mala MS, Bejai V, et al. Application of illuminoscope in smartphone micrography. Indian Dermatology Online Journal. 2016;7(5):432. https://doi.org/10.4103/2229-5178.190499

4. Börve A, Terstappen K, Sandberg C, et al. Mobile teledermoscopy - there's an app for that! Dermatology Practical \& Conceptual. 2013;3(2):41.

DOI: https://doi.org/10.5826/dpc.0302a05

5. Kroemer S, Frühauf J, Campbell T, et al. Mobile teledermatology for skin tumour 
screening: diagnostic accuracy of clinical and dermoscopic image tele-evaluation using cellular phones. British Journal of Dermatology. 2011;164(5):973-9.

DOI: https://doi.org/10.1111/j.1365-2133.2011.10208.x

6. Khalbuss WE, Cuda J, Cucoranu IC. Screening and dotting virtual slides: A new challenge for cytotechnologists. CytoJournal. 2013;10:22. DOI: https://doi.org/10.4103/17426413.120790

7. Ganapathy K, Ravindra A. mHealth: A potential tool for health care delivery in India: Rockefeller foundation; 2008.

8. August T, Harvey M, Lightfoot P, et al. Emerging technologies for biological recording. Biological Journal of the Linnean Society. 2015;115(3):731-49.

DOI: https://doi.org/10.1111/bij.12534

9. Shin D, Pierce MC, Gillenwater AM, et al. A fiber-optic fluorescence microscope using a consumer-grade digital camera for in vivo cellular imaging. PLoS ONE. 2010;5(6):e11218. DOI: https://doi.org/10.1371/journal.pone.0011218

10. Roy S, Pantanowitz L, Amin M, et al. Smartphone adapters for digital photomicrography. Journal of Pathology Informatics. 2014;5:24. DOI: https://doi.org/10.4103/2153-3539.137728

11.Switz NA, D'Ambrosio MV, Fletcher DA. Low-cost mobile phone microscopy with a reversed mobile phone camera lens. PLoS ONE. 2014;9(5):e95330.

DOI: https://doi.org/10.1371/journal.pone.0095330

12.Desai NJ, Gupta B, Patel PN, et al. A comparative study of microscopic images captured by a box type digital camera versus a standard microscopic photography camera unit. Journal of Clinical and Diagnostic Research. 2014;8(10):FC23. https://doi.org/10.7860/JCDR/2014/9445.5029

DOI:

13.Limmeren R, Chevrollier N, Esser P, et al. Microscope and Mobile Phones: Product Development in Uganda. 2009.

14.Bellina L, Missoni E. Mobile cellphones (M-phones) in telemicroscopy: increasing connectivity of isolated laboratories. Diagnostic Pathology. 2009;4(1):19.

DOI: https://doi.org/10.1186/1746-1596-4-19

15.Frean J. Microscopic images transmitted by mobile cameraphone. Transactions of the Royal Society of Tropical Medicine and Hygiene. 2007;101(10):1053. DOI: https://doi.org/10.1016/j.trstmh.2007.06.008
16.Godse C, Patkar S, Nabar N, et al. Mobile Camera Microphotography: A Simple But Elegant Technique For Telediagnosis of Malaria. JK Science. 2008;10(3):155-156.

17.Tseng D, Mudanyali O, Oztoprak C, et al. Lensfree microscopy on a cellphone. Lab on a Chip. 2010;10(14):1787-92. DOI: https://doi.org/10.1039/C003477K

18. Breslauer DN, Maamari RN, Switz NA, et al. Mobile phone based clinical microscopy for global health applications. PLoS ONE. 2009;4(7):e6320. $\quad$ DOI: https://doi.org/10.1371/journal.pone.0006320

19. $\mathrm{Yu} \mathrm{H}$, Gao F, Jiang $L$, et al. Development of a Whole Slide Imaging System on Smartphones and Evaluation With Frozen Section Samples. JMIR mHealth and uHealth. 2017;5(9):e132.

DOI: https://doi.org/10.2196/mhealth.8242

20. Yahya H, Ayuba G. Smartphone photomicrography: A quick, easy, useful technique for the clinician. Nigerian Journal of Clinical Practice. 2017;20(2):264-265. DOI: https://doi.org/10.4103/1119-3077.198312

21.Zhou C, Yu Y, Xue R, et al. Highquality digital photomicrography utilizing a smartphone without adapter. Journal of Cutaneous Pathology. 2016;43(1):82-4. DOI: https://doi.org/10.1111/cup.12561

22. Morrison AS, Gardner JM. Smart phone microscopic photography: a novel tool for physicians and trainees. Archives of Pathology and Laboratory Medicine. 2013;138(8):1002. DOI: https://doi.org/10.5858/arpa.2013-0425-ED

23. Morrison AO, Gardner JM. The Morrison technique: a free-hand method for capturing photomicrographs using a smartphone. Journal of Cutaneous Pathology. 2016;43(5):4724. DOI: https://doi.org/10.1111/cup.12650

24.Jung D, Choi J-H, Kim S, et al. Smartphone-based multi-contrast microscope using color-multiplexed illumination. Scientific Reports. 2017;7(1):7564. DOI: https://doi.org/10.1038/s41598-017-07703-w

25. Mondal H, Mondal S, Das D. Development of a simple smartphone adapter for digital photomicrography. Indian Dermatology Online Journal. 2017;8(6):485-6.

26. Singaravel S, Aleem MA. Hands-free: a low-cost adapter for smartphone microscopic photography using a cardboard toilet-paper roll. Archives of Pathology and Laboratory Medicine. 2016;140(8):741-3. DOI: https://doi.org/10.5858/arpa.2016-0081-LE 
27. Kanakasabapathy MK, Sadasivam M, Singh A, et al. An automated smartphone-based diagnostic assay for point-of-care semen analysis. Science Translational Medicine. 2017;9(382):eaai7863. DOI: https://doi.org/10.1126/scitranslmed.aai7863 28.Méndez-Rosado LA， Quiñones O, Molina $\mathrm{O}$ et al. Antenatal Cytogenetic Testing in Havana, Cuba. MEDICC Rev. 2014 Jul-Oct;16(34): 27-34. https://doi.org/10.37757/MR2014V14.7 29.Balsam J, Bruck HA, Kostov Y, Rasooly A. Image stacking approach to increase sensitivity of fluorescence detection using a low cost complementary metal-oxide-semiconductor (CMOS) webcam. Sensors and Actuators, B: Chemical. 2012;171:141-7. DOI: https://doi.org/10.1016/j.snb.2012.02.003

Received 1 October 2020

Revised 3 November 2020

Accepted 10 November 2020

\section{Information about the authors}

Arlay C. López, Degree in Biochemistry, Researcher at the National Center of Medical
Genetics, Havana, Cuba, E-mail: arlay@cngen.sld.cu, ORCID: 0000-0002-4145432X.

Michel S. Torres, MsC, Degree in Microbiology, Master in Bioinformatics, Assistant Professor, Assistant Researcher at the National Center of Medical Genetics, Havana, Cuba, E-mail: michel.soriano@cngen.sld.cu, ORCID: 00000003-3335-8669.

Nereida G. García, Degree in Biology, Master in Medical Genetics, Research Associate at the National Center of Medical Genetics, Havana, Cuba, E-mail: nellig@infomed.sld.cu, ORCID: 00000003-1019-8877.

Ursulina S, Mayedo, Technician in Microbiology, Researcher at the National Center of Medical Genetics, Havana, Cuba, E-mail: ursulinasm@infomed.sld.cu, ORCID:0000-00026154-1017.

Luis A. Méndez-Rosado,Degree in Biology, Master in Medical Genetics, PhD, Full Professor, Full Researcher at the National Center of Medical Genetics, Havana, Cuba, E-mail: albermen@infomed.sld.cu, ORCID: 0000-0002-44010054 . 